\title{
Required Longitudinal Service-Learning and Its Effects on Medical Students' Attitudes Toward the Underserved
}

\author{
Monica Rose Arebalos ${ }^{1} \mathbb{D} \cdot$ Faun Lee Botor ${ }^{1} \cdot$ Edward Simanton $^{1} \cdot$ Jennifer Young ${ }^{1}$
}

Accepted: 8 June 2021 / Published online: 18 June 2021

(c) The Author(s) 2021

\begin{abstract}
Although medical students enter medicine with altruistic motives and seek to serve indigent populations, studies show that medical students' attitudes towards the undeserved tend to worsen significantly as they go through their medical education. This finding emphasizes the need for medical educators to implement activities such as service-learning that may help mitigate this negative trend.

All students at the University of Nevada Las Vegas (UNLV) School of Medicine are required to participate in longitudinal service-learning throughout medical school, and a majority of students interact with the underserved at their service-learning sites. Using the previously validated Medical Student Attitudes Towards the Underserved (MSATU), independent sample T-tests showed that students who interact with underserved populations at their sites scored with significantly better attitudes towards the underserved at the end of their preclinical phase. Subjects included 58 medical students with 100\% taking the MSATU. This result indicates that longitudinal service-learning, particularly when it includes interaction with the underserved, can be one method to combat the worsening of medical students' attitudes as they complete their medical education.
\end{abstract}

Keywords Medical education $\cdot$ Community-oriented $\cdot$ Ethics/attitudes $\cdot$ Public health

\section{Introduction}

The USA is currently challenged by striking disparities in health, and the growing diversity in US society has supported the need for culturally competent medical professionals [1]. Although many students enter medical school hoping to reach indigent populations, studies continue to show that medical students' attitudes towards the underserved worsen significantly as they complete their medical education [2-7].

One intervention that may help mitigate this pattern is service-learning. Service-learning is defined as an "educational experience in which students participate in an organized service activity that meets identified community needs" and includes reflection on the service in order to gain an enhanced sense of civic responsibility [8]. A systematic review found considerable variability in program types with various names including service-learning, communityoriented learning, and community-based learning. Despite

Monica Rose Arebalos

arebalos@unlv.nevada.edu

1 University of Nevada Las Vegas School of Medicine, Las Vegas, NV 89102, USA these variations, there is still evidence that service is beneficial for both the community and the medical students [9]. For many institutions, the goal of service-learning is for students to learn about population health and to promote and improve public health skills [10]. Many studies have shown that service activities are correlated with higher levels of empathy, better understanding of community needs, and an increased belief that physicians have a responsibility to provide medical care for the needy [11-15]. Additionally, when studies specifically compare groups of students who participate in some type of community service to those that do not, results suggest that attitudes towards the underserved are consistently better in service groups [16-19]. The Liaison Committee on Medical Education has recognized the potential positive implications of service-learning and has added a mandate to their standards that medical schools "provide sufficient opportunities for, encourage, and support medical student participation in service-learning and/or community service activities" [20].

While studies show promising positive outcomes of service-learning, most activities tend to be short-term or voluntary for students. None of the authors are aware of any medical school in the USA where service-learning is 
required across multiple years of the curriculum for all students. In an attempt to train compassionate physicians who will "understand and value all cultural aspects of medicine" [21], the University of Nevada Las Vegas (UNLV) School of Medicine became one of the few medical schools to require all students to participate in longitudinal service-learning throughout their doctorate education. As a new school, UNLV has partnered with over 50 organizations as community service sites. Shortly after beginning medical school, all students select a service-learning site. During the preclinical phase, students have scheduled time to complete at least 4 hours of service each month. During the clinical phase, service activities are more sporadic as they can fit within clerkship schedules. Students also participate in written reflections and continuous collaboration with their organization regarding goals and projects.

The purpose of this study is to analyze if required longitudinal service-learning influences students' attitudes towards the underserved during the preclinical phase. Additionally, the purpose is to examine possible differences in attitudes between students who work directly with the underserved versus those that do not. Our hypothesis is that the results of a validated survey will demonstrate that required servicelearning mitigates some of the decrease of attitudes towards the underserved, especially in students who work closely with underserved populations.

\section{Methods}

\section{Instruments}

The Medical Student Attitudes Towards the Underserved (MSATU) is a validated self-reported measure of medical students' attitudes with regard to providing medical care to underserved populations. This measure consists of three subsections related to healthcare services, access to care, and US influences. The first section focuses on the responsibility of various groups (medical students, physicians, the government, etc.) in providing healthcare services to patients in indigent populations. The second section surveys the student's opinion on whether patients should have access to various types of medical care services. The third section surveys students' perception on how being a patient in the USA influences various aspects of medical care. The MSATU elicits responses on a 5 -point Likert scale $(1=$ strongly disagree, $5=$ strongly agree) $[3,6,16]$. We used all three subsections to calculate each students' total MSATU score.

\section{Data Collection}

All medical students in the class of $2021(n=58)$ received the MSATU prior to medical school and at the end of the 18-month preclinical phase. The survey was a confidential online survey students took at a time and location of their choosing.

Students were classified into two groups: those who interact with the underserved at their service-learning sites $(n=46)$ and those who do not $(n=12)$. Classification of groups was performed by the course director at the end of the preclinical phase based on organizations' missions and self-reported activities. The sites that provide direct interaction with the underserved do so through activities such as mentorship, advocacy, or tutoring. Some examples of sites that include interaction are the following: Boys and Girls Clubs or other after-school programs, Rape Crisis and Human Trafficking Intervention, and Big Brothers Big Sisters. Sites without direct interaction with the underserved focused on a social determinant issue such as transportation, food insecurity, or housing. Students in this group augmented the organization's internal activities and programs or conducted outreach with the general public rather than directly interacting with the underserved. Students selected their service sites and thus made their own decision regarding the amount of interaction they would have with the underserved.

\section{Analysis}

Mean scores were calculated for each of the three subsections and the total MSATU. Changes in attitudes were calculated by subtracting the pretest score from the posttest score for each participant. Independent sample t-tests were used to examine differences between the experimental groups (those who interacted with the underserved, and those who did not). SPSS version 26.0 was used for all statistical analyses.

\section{Results}

Fifty-eight students completed the MSATU, yielding a 100\% completion rate. Regarding sociodemographic characteristics, students in this sample were 29 males and 29 females with 15 being considered underrepresented minority students (25.9\%).

As demonstrated in Tables 1 and 2, students who interacted with the underserved in their service-learning began with very similar pretest scores but showed significantly less decrease in attitudes toward the underserved on the healthcare services subsection of the MSATU. While students who selected service sites that did not involve interaction with the underserved appeared to score lower on most of the pretest subscales, these differences were not statistically significant. 
Table 1 Means and standard deviations of MSATU subscales and totals by group

\begin{tabular}{|c|c|c|c|c|c|}
\hline & & \multicolumn{2}{|c|}{$\begin{array}{l}\text { Interacted with } \\
\text { underserved } \\
(\mathrm{N}=46)\end{array}$} & \multicolumn{2}{|c|}{$\begin{array}{l}\text { No underserved } \\
\text { interaction } \\
(\mathrm{N}=12)\end{array}$} \\
\hline & & Mean & SD & Mean & SD \\
\hline \multirow[t]{4}{*}{ Pretest } & Healthcare services subscale & 4.037 & 0.389 & 3.941 & 0.279 \\
\hline & Access to care subscale & 4.380 & 0.691 & 4.097 & 0.630 \\
\hline & USA influence subscale & 4.279 & 0.560 & 4.010 & 0.566 \\
\hline & Total MSATU & 4.231 & 0.458 & 4.015 & 0.465 \\
\hline \multirow[t]{4}{*}{ Post-test } & Healthcare services subscale & 3.993 & 0.421 & 3.698 & 0.547 \\
\hline & Access to care subscale & 4.292 & 0.712 & 4.214 & 0.589 \\
\hline & USA influences subscale & 4.310 & 0.540 & 3.917 & 0.883 \\
\hline & Total MSATU & 4.199 & 0.426 & 3.943 & 0.600 \\
\hline \multirow[t]{4}{*}{ Change } & Healthcare services subscale & -0.044 & 0.286 & -0.243 & 0.316 \\
\hline & Access to care subscale & -0.087 & 0.472 & 0.118 & 0.321 \\
\hline & USA influence subscale & 0.031 & 0.577 & -0.093 & 0.802 \\
\hline & Total MSATU & -0.032 & 0.299 & -0.073 & 0.360 \\
\hline
\end{tabular}

\section{Discussion}

Our students' attitudes toward the underserved were shown to remain stable when they interact with underserved at their service-learning site, rather than worsen significantly as previous studies have shown is typical in undergraduate medical education. Although we hypothesized that all students who participate in service-learning would benefit, the discovery that only students who interact with the underserved demonstrated relatively stable attitudes was an important finding. This implies that educators who begin to implement required service-learning should consider ensuring their students that they will be interacting with underserved communities.

While the worsening of medical students' attitudes toward indigent populations is a recognized problem in medical education, not all medical schools are surveying their students in order to measure the extent of the problem or its progression over time. In fact, in many aspects of medical school, evaluations of students' knowledge, skills, and attitudes are done in a variety of ways, many of which are not standardized [22]. Implementing validated measures such as the MSATU will be an important step in reaching the goal of training socially responsible physicians. By measuring their students' attitudes, educators will be able to evaluate if interventions such as service-learning are necessary and can evaluate the effectiveness of the interventions.

Despite the fact that all of our students participate in longitudinal service-learning, the actual interaction with underserved populations appears to be the most important component of this innovation. Medical science educators who hope to improve their students' attitudes toward indigent populations, and possibly help their students remember their initial philanthropic motives for entering medicine,

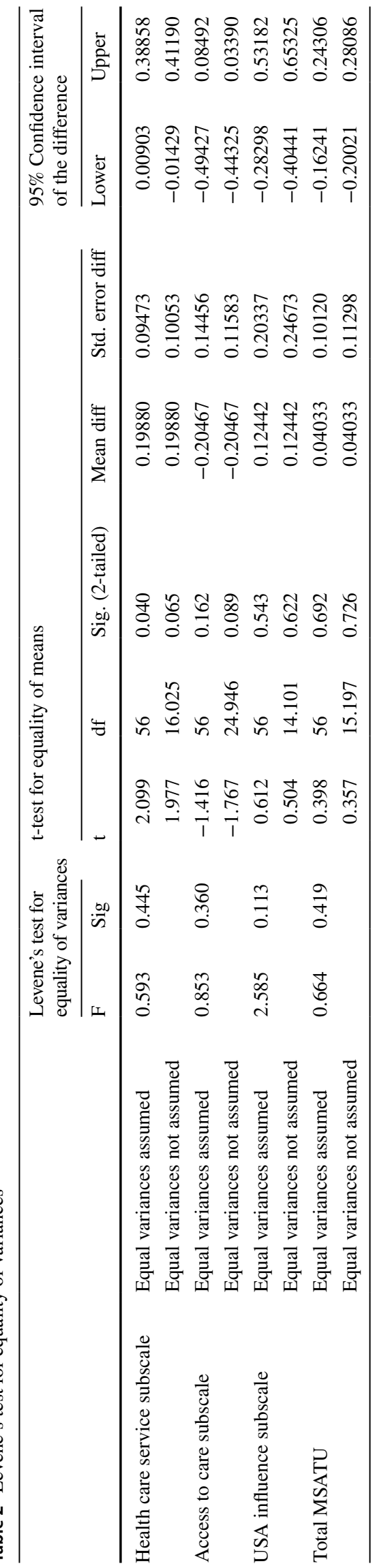


should consider implementing service activities in their curricula that include meaningful interactions with underserved populations.

\section{Conclusion}

Medical students' attitudes toward the underserved tend to worsen as they complete 4 years of medical school. This is a significant problem in medical education that will require multidisciplinary innovations on multiple levels, and the implementation of service-learning with the underserved may be an important component of the solution. The purpose of our study was to evaluate if required longitudinal servicelearning was beneficial in mitigating these worsening attitudes. While all medical students were required to participate in longitudinal service-learning, only those who worked directly with underserved communities showed stable and significantly more positive attitudes than their counterparts who did not interact with the underserved. These findings can help guide medical science educators in creating meaningful experiences that help their students maintain the altruistic attitudes that they start medical school with, and to become the compassionate physicians they desire to be.

\section{Limitations of the Study}

The UNLV School of Medicine at its foundation is designed to be geared toward community service, and students are aware of this as they apply. It is possible that students who elect to come to UNLV may be different from medical students nationwide in their focus on community service.

Before students start volunteering at their service-learning sites, they begin medical school with an introductory block in which they, in part, learn about various population health topics while completing participatory community learning activities in an assigned underserved area. All students also create a presentation about population health topics that they have witnessed in their assigned areas struggling with. It is possible that beginning medical school with this emphasis on population health may prime students to be more community-oriented and bring their altruistic motives into focus before they begin their longitudinal service-learning activities.

This study is based on a single cohort of 58 students only in the preclinical phase at a new medical school. Future studies will look at different kinds of service-learning over all 4 years of the medical curriculum. Due to the servicelearning requirements, we do not have a control group of students without any service-learning exposure to compare to. Also, future cohorts may react differently to the servicelearning activities.
Acknowledgements Dr. Barbara Atkinson was the visionary Founding Dean of UNLV School of Medicine who created a new medical school with an emphasis on community interaction and service. Dr. Laura Culley is the Dean of Community Engagement who built the relationships and service-learning curriculum described in this study. Without her work building these connections, none of this would have been possible. We thank the community organizations who have welcomed our medical students for their service-learning.

Author Contribution All authors contributed to the study conception and design. Data collection and analysis were performed by Jennifer Young and Edward Simanton. The first draft of the manuscript was written by Monica Rose Arebalos and Faun Lee Botor, and all authors commented on previous versions of the manuscript and assisted in the editing process. All authors read and approved the final manuscript.

\section{Declarations}

Ethics Approval This study was conducted with approval of the UNLV IRB (April 3, 2017. Protocol \#1,030,906).

Conflict of Interest The authors declare no competing interests.

Open Access This article is licensed under a Creative Commons Attribution 4.0 International License, which permits use, sharing, adaptation, distribution and reproduction in any medium or format, as long as you give appropriate credit to the original author(s) and the source, provide a link to the Creative Commons licence, and indicate if changes were made. The images or other third party material in this article are included in the article's Creative Commons licence, unless indicated otherwise in a credit line to the material. If material is not included in the article's Creative Commons licence and your intended use is not permitted by statutory regulation or exceeds the permitted use, you will need to obtain permission directly from the copyright holder. To view a copy of this licence, visit http://creativecommons.org/licenses/by/4.0/.

\section{References}

1. Njoku DrPH, Anuli MPH, Baker PhD, Uchenna MEd. Teaching about cultural competence and health disparities in an online graduate public health course. J Health Dispar Res Pract. 2018;12(2):14-39. Retrieved from https://digitalscholarship.unlv. edu/jhdrp/vol12/iss $2 / 2$.

2. Rezler AG. Attitude changes during medical school: a review of the literature. J Med Educ. 1974;49:1023-30.

3. Crandall SJS, Volk RJ, Loemker V. Medical students' attitudes towards providing health care to the underserved: are we training socially responsible physicians. JAMA. 1993;269(19):54.

4. Crandall S, Reboussin B, Michielutte R, Anthony J, Naughton M. Medical students' attitudes toward underserved patients: a longitudinal comparison of problem-based and traditional medical curricula. Adv Health Sci Educ Theory Pract. 2007;12(1):7186. https://doi.org/10.1007/s10459-005-2297-1. Retrieved from https://www.ncbi.nlm.nih.gov/pubmed/17041814.

5. Crandall SJ, Davis SW, Broeseker AE, Hildebrandt C. A longitudinal comparison of pharmacy and medical students' attitudes toward the medically underserved. Am J Pharm Educ. 2008;72(6):148. https://doi.org/10.5688/aj7206148. Retrieved from https://www.ncbi.nlm.nih.gov/pubmed/19325964.

6. Stephens MB, Landers G, Davis SW, Durning SJ, Crandall SJ. Medical student attitudes toward the medically underserved: the USU perspective. Military Med. 2015;180(4 Suppl), 61-63. 
doi:https://doi.org/10.7205/MILMED-D-14-00558. Retrieved from https://www.ncbi.nlm.nih.gov/pubmed/25850128.

7. Mor Z, Cadesky A, Halleluyan R, Sheffer R. Attitudes of Israeli medical students towards the medical treatment of uninsured migrants. BMC Med Educ. 2020;20(1):72. https://doi.org/10. 1186/s12909-020-1973-4. Retrieved from https://www.ncbi.nlm. nih.gov/pubmed/32171315.

8. Bringle RG, Hatcher JA. Campus-community partnerships: the terms of engagement. J Soc Issues. 2002;58(3):503-516. https://doi.org/10. 1111/1540-4560.00273. Retrieved from https://onlinelibrary.wiley. com/doi/abs/https://doi.org/10.1111/1540-4560.00273.

9. Hunt JB, Bonham C, Jones L. Understanding the goals of service learning and community-based medical education: a systematic review. Academic medicine : J Assoc Am Med Colleges. 2011;86(2):246251. https://doi.org/10.1097/ACM.0b013e3182046481. Retrieved from https://www.ncbi.nlm.nih.gov/pubmed/21169780.

10. Essa-Hadad J, Murdoch-Eaton D, Rudolf MC. What impact does community service learning have on medical students' appreciation of population health? Public Health. 2015;129(11):1444-51. https://doi.org/10.1016/j.puhe.2015.05.009.

11. Meili R, Fuller D, Lydiate J. Teaching social accountability by making the links: qualitative evaluation of student experiences in a service-learning project. Med Teach. 2011;33(8):659-666. doi:https://doi.org/10.3109/0142159X.2010.530308. Retrieved from http://www.tandfonline.com/doi/abs/https://doi.org/10.3109/ 0142159X.2010.530308.

12. Lee WK, Harris CCD, Mortensen KA, Long LM, Sugimoto-Matsuda J. Enhancing student perspectives of humanism in medicine: reflections from the Kalaupapa service learning project. BMC Med Educ. 2016;16(1):137. https://doi.org/10.1186/s12909-016-0664-7. Retrieved from https://www.ncbi.nlm.nih.gov/pubmed/27159976.

13. Loh AZH, Tan JSY, Lee JJ, Koh GC. Voluntary community service in medical school: a qualitative study on student leaders' motivations, experiences, and outcomes. Med Teach. 2016;38(7):683-690. doi:https://doi.org/10.3109/0142159X. 2016.1150985. Retrieved from https://www.tandfonline.com/doi/ abs/https://doi.org/10.3109/0142159X.2016.1150985.

14. Hand J, Koransky A, Feinman J, Pellerano MB, Jimenez ME, Giordano S, Jahn E. Alumni perspectives on the role of medical school service learning experiences in their professional development and practice. J Health Care Poor Unders. 2018;29(4):13861399. doi:https://doi.org/10.1353/hpu.2018.0102. Retrieved from https://muse.jhu.edu/article/708248.

15. Sin D, Chew T, Chia TK, Ser JS, Sayampanathan A, Koh G. Evaluation of constructing care collaboration - nurturing empathy and peer-to-peer learning in medical students who participate in voluntary structured service learning programmes for migrant workers. BMC Med Educ. 2019;19(1):304. https://doi.org/10.1186/ s12909-019-1740-6. Retrieved from https://www.ncbi.nlm.nih. gov/pubmed/31395101.

16. Briggs AM, Wang SY, Bhowmik S, Wasag J, Pinto-Powell RC. The beyond the books program: improving medical student attitudes toward the underserved. Health Equity. 2018;2(1):98-102. doi:https://doi.org/10.1089/heq.2018.0015. Retrieved from https:// www.liebertpub.com/doi/abs/https://doi.org/10.1089/heq.2018. 0015.

17. Brazeau CM, Schroeder R, Rovi S, Boyd L. Relationship between medical student service and empathy. Academic medicine : J Assoc Am Med Colleges. 2011:86(10 Suppl) S42-S45. https:// doi.org/10.1097/ACM.0b013e31822a6ae0. Retrieved from https:// www.ncbi.nlm.nih.gov/pubmed/21955767.

18. Elam CL, Sauer MJ, Stratton TD, Skelton J, Crocker, D, Musick DW. Service learning in the medical curriculum: developing and evaluating an elective experience. Teach Learn Med. 2003;15(3):194203. https://doi.org/10.1207/S15328015TLM1503_08. Retrieved from http://www.tandfonline.com/doi/abs/https://doi.org/10.1207/ S15328015TLM1503_08.

19. Jones K, Blinkhorn LM, Schumann S, Reddy ST. Promoting sustainable community service in the 4 th year of medical school: a longitudinal service-learning elective. Teach Learn Medicine. 2014:26(3):296-303. https://doi.org/10.1080/10401334. 2014.911698. Retrieved from https://www.tandfonline.com/doi/ abs/https://doi.org/10.1080/10401334.2014.911698.

20. Association of American Medical Colleges (AAMC) and American Medical Association (AMA). Functions and structure of a medical school: standards for accreditation of medical education programs leading to the MD Degree: Liaison Committee On Medical Education (LCME). 2020. https://lcme.org/publications/.

21. University of Nevada Las Vegas. UNLV School of Medicine: leadership and mission. Retrieved from https://www.unlv.edu/medicine/ student-handbook/section1.

22. Barzansky B, Etzel SI. Educational programs in US medical schools, 2002-2003. JAMA. 2003;290(9):1190-6. https://doi. org/10.1001/jama.290.9.1190.

Publisher's Note Springer Nature remains neutral with regard to jurisdictional claims in published maps and institutional affiliations. 